\title{
Case Report: Kikuchi-Fujimoto Disease: A case of
}

\section{supraclavicular lymphadenopathy [version 1; peer review: 1}

\section{approved, 1 approved with reservations]}

\author{
Shiza Sarfraz (D1) Hamza Rafique1, Hassam Ali(iD), Syed Zawahir Hassan (iD2 \\ ${ }^{1}$ Quaid-e-azam Medical College, Bhawalpur, Pakistan \\ 2Internal Medicine, Park Plaza Hospital, Houston, USA
}

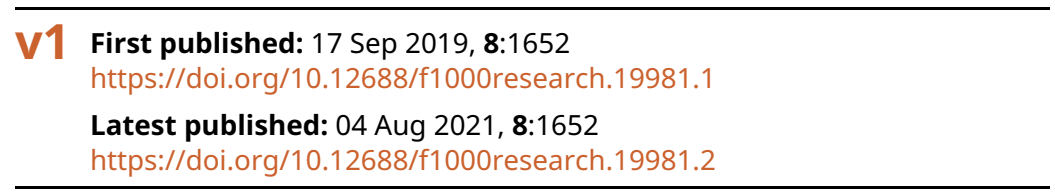

\section{Abstract}

Kikuchi-Fujimoto Disease (KFD), also known

as histiocytic necrotizing lymphadenitis, is a rare cause of cervical

lymphadenopathy. Patients usually present with localized

lymphadenopathy, fever and fatigue. Because of the poorly understood etiology, it can be mistaken for an infectious disease or even malignance. Here we discuss a case of KFD that initially presented with left sided cervical lymphadenopathy that later progressed to left supraclavicular lymph nodes. Due to its characteristic overlap with other disorders like tuberculous lymphadenitis and lymphoma, KFD remains an arduous diagnosis for physicians. Therefore, one should be made aware of symptoms that can lead to misdiagnosis in patients.

\section{Keywords}

Lymphadenitis, Cervical lymphadenopathy, Tuberculosis, Lymphoma,

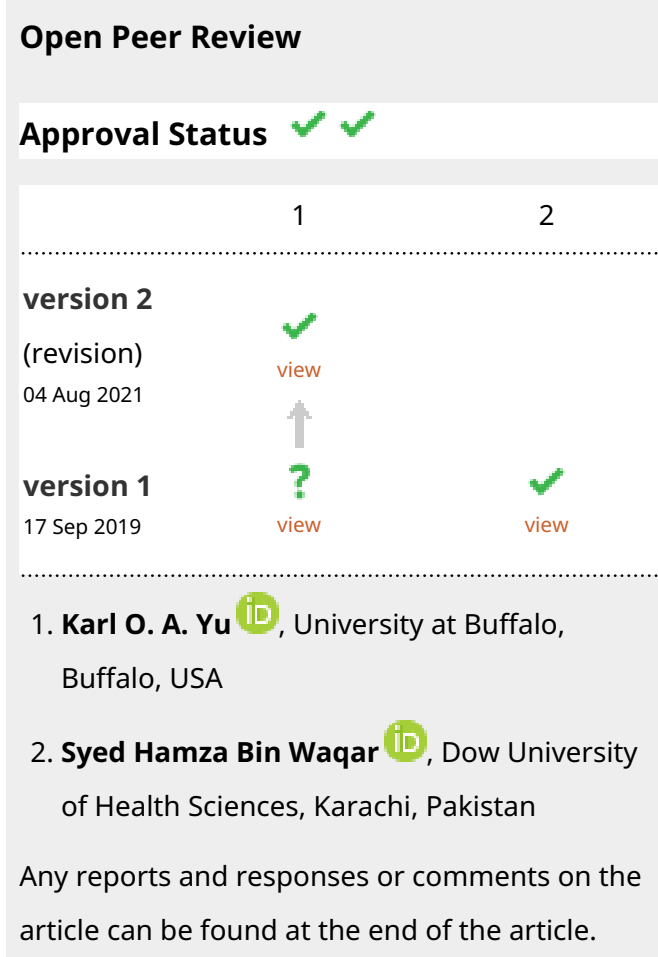

Corresponding authors: Shiza Sarfraz (Shizasarfraz53@gmail.com), Syed Zawahir Hassan (drzawahir@gmail.com)

Author roles: Sarfraz S: Writing - Original Draft Preparation; Rafique H: Writing - Original Draft Preparation; Ali H: Writing - Original Draft Preparation; Hassan SZ: Formal Analysis, Writing - Review \& Editing

Competing interests: No competing interests were disclosed.

Grant information: The author(s) declared that no grants were involved in supporting this work.

Copyright: @ 2019 Sarfraz S et al. This is an open access article distributed under the terms of the Creative Commons Attribution License , which permits unrestricted use, distribution, and reproduction in any medium, provided the original work is properly cited.

How to cite this article: Sarfraz S, Rafique H, Ali H and Hassan SZ. Case Report: Kikuchi-Fujimoto Disease: A case of supraclavicular lymphadenopathy [version 1; peer review: 1 approved, 1 approved with reservations] F1000Research 2019, 8:1652

https://doi.org/10.12688/f1000research.19981.1

First published: 17 Sep 2019, 8:1652 https://doi.org/10.12688/f1000research.19981.1 


\section{Introduction}

Kikuchi-Fujimoto Disease (KFD) is known to occur both in the juvenile and adult population. The first case of reported Kikuchi Fujimoto disease was in Japan in 1972 and since then this disease has been described worldwide, with most cases reported in Asia ${ }^{1,2}$. Kikuchi-Fujimoto Disease typically follows a benign and self-limited course, characterized by cervical lymphadenopathy (most common). Less frequently, other symptoms might also be present like nausea, weight loss, night sweats and fatigue ${ }^{1}$. Generally, KFD is diagnosed via excisional lymph node biopsy and histopathological analysis. KFD shares many characteristics with other causes of lymphadenopathy including lymphoma, inflammatory disorders, autoimmune conditions, and infectious causes of lymphadenopathy like tuberculosis infection; therefore, it is important consider KFD in cases of persistent lymphadenopathy and must be differentiated from these conditions ${ }^{1,3}$. Treatment is mostly symptomatic with antipyretics, non-steroidal antiinflammatory drugs (NSAIDS) or on rare occasions, steroids. $\mathrm{KFD}$ is associated with spontaneous recovery in 1-4 months $\mathrm{s}^{4,5}$.

\section{Case presentation}

A 25y/o South East Asian male medical student presented in our outpatient department in January 2018 with left-sided cervical lymphadenopathy. The patient reported small bulges along the left side of his neck for one month. Associated symptoms included one month of low-grade fever and fatigue. There was no history of night sweats or reported weight loss. A course of antibiotics two weeks earlier did not improve his symptoms. On presentation, the patient was hemodynamically stable with a temperature of $100.1^{\circ} \mathrm{C}$, heart rate of 98 beats $/ \mathrm{min}$, respiratory rate was 18 breaths/min and blood pressure was $115 / 80 \mathrm{~mm} / \mathrm{hg}$. On physical examination there was diffuse left cervical and supraclavicular lymphadenopathy. Lymph nodes were rubbery, soft and mobile. There were no changes in hands, eyes or ears. His nose and throat examination were normal. On auscultation of the chest, breath sounds were normal bilaterally and normal heart sounds where present. The abdominal examination was also normal. Initial lab investigations included complete blood count with total and differential leukocyte count, metabolic profile, erythrocyte sedimentation rate (ESR) and lactate dehydrogenase (LDH). This was to rule out any possibility of lymphadenitis, or neoplastic disorder. On laboratory examination there was an increase in lymphocytes and an increase in inflammatory markers including ESR and LDH (Table 1).

A provisional diagnosis of tuberculous lymphadenitis was made based on his occupation. Further investigations were ordered to determine the size and extent of the lymphadenopathy. These included ultrasonography of the neck and abdomen, to visualize any hidden lymphadenopathy that might have been missed during the initial physical examination; chest $\mathrm{x}$-ray, to rule out any active tuberculosis; and interferon-gamma release assay.

On ultrasonography (Figure 1), the patient showed enlarged multiple discrete left cervical and supraclavicular lymph nodes measuring up to $16 \times 10 \mathrm{~mm}$. The rest of the ultrasound report did not show any abnormalities. Chest $\mathrm{x}$-ray was normal and interferon-gamma release assay was not conclusive.

To ensure a definitive diagnosis, surgery with lymph node excision and biopsy was performed. An excisional lymph node biopsy from the anterior cervical chain was performed and on histopathological analysis it showed necrotizing lymphadenitis

Table 1. Laboratory data.

\begin{tabular}{|l|l|l|l|}
\hline Variable & $\begin{array}{l}\text { Reference } \\
\text { range }\end{array}$ & Day 0 & Day 30 \\
\hline Hemoglobin (g/dl) & $12-16$ & 14.1 & 13.2 \\
\hline White blood cell count (c/mm) & $4000-11000$ & 5000 & 4600 \\
\hline Red blood cell count (million/c/mm) & $3.5-5.5$ & 4.49 & 4.38 \\
\hline Hematocrit (\%) & $36-53$ & 42.2 & 40.9 \\
\hline Mean corpuscular volume (fl) & $80-100$ & 94 & 93.4 \\
\hline Mean corpuscular hemoglobin (pg) & $26-34$ & 31.4 & 30.1 \\
\hline Mean corpuscular hemoglobin concentration (g/dl) & $31-37$ & 33.4 & 32.3 \\
\hline Platelet count (c/mm) & $150000-450000$ & 270000 & 206000 \\
\hline Erythrocyte sedimentation rate (mm/hr) & $0-20$ & 60 & 45 \\
\hline Differential & & & \\
\hline Neutrophils (\%) & $54-62$ & 53 & 62 \\
\hline Lymphocytes (\%) & $25-33$ & 40 & 33 \\
\hline Monocytes (\%) & $03-07$ & 3 & 3 \\
\hline Eosinophils (\%) & $01-06$ & 4 & 2 \\
\hline lactate dehydrogenase (u/l) & $225-400$ & 468 & 267 \\
\hline
\end{tabular}




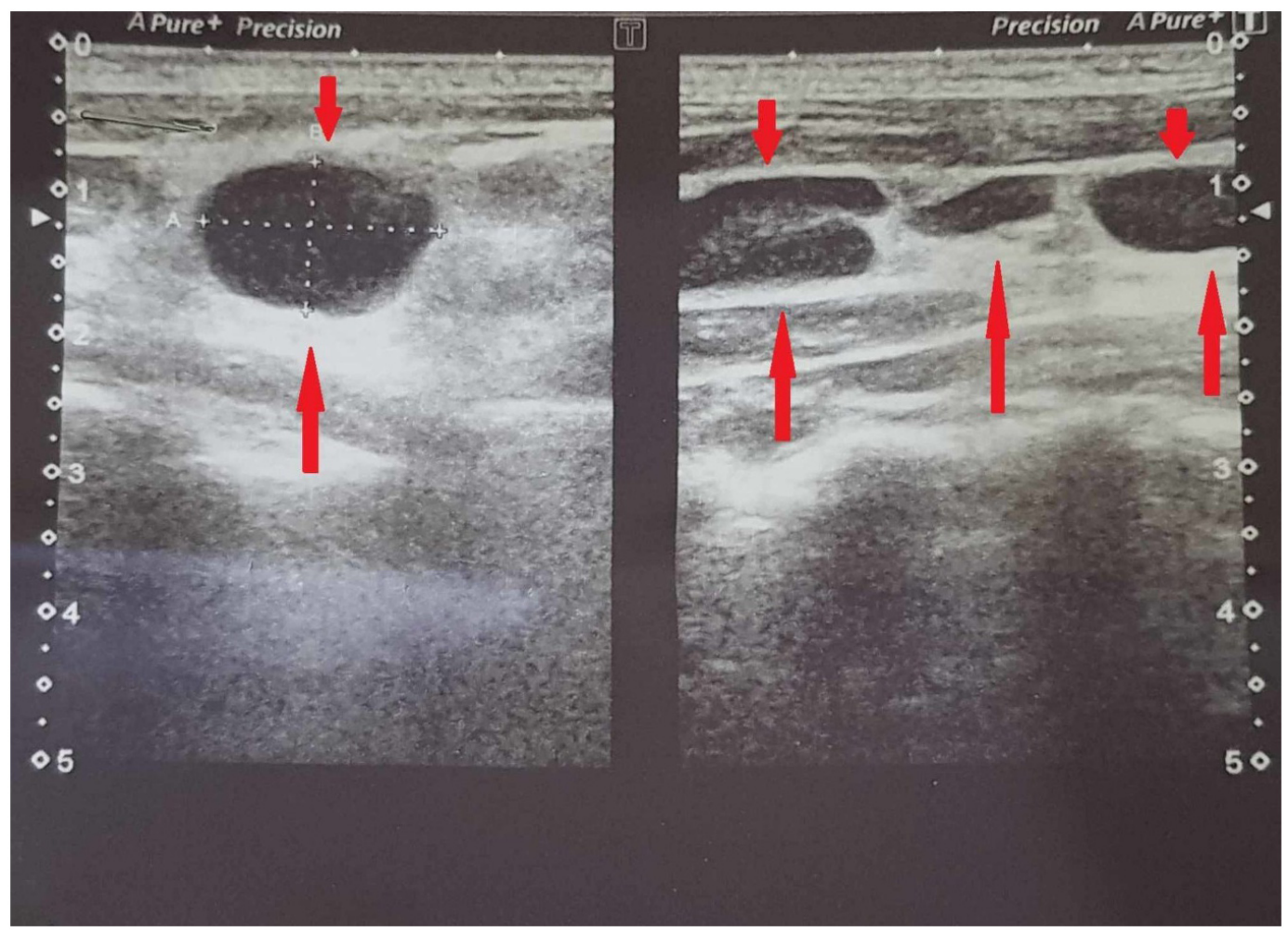

Figure 1. Ultrasound of neck showing enlarged supraclavicular and cervical and lymph nodes (Left side).

with partial alteration of structure by clusters of histiocytic and interspersed nuclear debris. In preserved areas, lymphoid follicles with pale staining germinal centers were also seen. No evidence of tuberculous granulomas or malignancy was found. Stains for acid fast bacteria were also negative.

It was decided that no antibiotics should be given to the patient at this time and watchful waiting was advised. For fever, $500 \mathrm{mg}$ paracetamol twice daily was prescribed for one week only. The patient was followed up twice a month in our outpatient clinic to monitor any spread of the lymphadenopathy. The disease course was uneventful. The patient was not given any further medication and watchful waiting was continued. Within two months the lymphadenopathy decreased dramatically, and the patient reported no fever. It completely disappeared in four months.

\section{Discussion}

The actual cause of KFD is still unknown but it has been proposed to have infectious and immunological etiologies ${ }^{1}$. This disease is thought to be a hyperimmune response to infectious, physical or chemical agents. Some of the unidentified agents may include toxoplasmosis, Brucella, Bartonella henslae, Yersinia enterolitica, human herpes virus, Ebstein Bar virus, parainfluenza, paramyxovirus, parvovirus B19, cytomegalovirus and human immunodeficiency virus ${ }^{1,3-5}$. However, serological and molecular studies have been unable to identify a single specific pathogen. Due to this reason, KFD diagnosis is markedly limited to invasive procedures like excisional biopsy (to observe cellular changes) and not just physical examination and history.

Prevalence of Kikuchi disease has been seen highest amongst the Japanese population and people from East Asia but more recently this disease has been reported all over the world ${ }^{2}$. Our case is from South East Asia, Pakistan.

Typically young adults (aged 20-30) are affected, but it does not seem to spare any age group as cases have been reported in the pediatric population as well, which can be seen in the reports of Byun $\mathrm{JH}^{6}$. However, the case report by Byun JH shows that, when Kikuchi disease occurs in children, it often involves the central nervous system leading to meningitis and encephalitis.

As reported by Deaver et al. ${ }^{7}$, clinical course of this disease has some specific and non-specific features with the specific one being unilateral cervical lymphadenopathy. Although 
lymphadenopathy is commonly found in cervical lymph nodes other groups such as the axillary and mediastinal lymph nodes may also be involved. Unexplained fever and night sweats are also among the common clinical presentations ${ }^{8}$. Our patient also presented with all the above listed common complaints. Less common complaints include headache, fatigue, arthralgia, myalgia, night sweats, weight loss, rash and abdominal pain $^{8}$. Our patient experienced none of them except fatigue. Although rare, patient may present with the involvement of central nervous system and peripheral nervous system?.

Confirmation of diagnosis is done by lymph node biopsy and histopathological analysis which shows distorted nodal architecture. The nodules are mostly necrotic and have debris from nuclear fragmentations due to cellular apoptosis. These necrotic foci are either isolated or clumped together. In addition, there is presence of proliferating histiocytic, $\mathrm{T}$ lymphocytes (CD8) and immunoblasts? ${ }^{7}$ The minimum criteria for KFD diagnosis is presence of aggregated histiocytic with occasional crescent-shaped nuclei, plasmacytoid histiocytic, and scattered karyorrhexis ${ }^{7}$. The biopsy results of our patient were quite similar, making KFD our primary diagnosis. Due to similar clinical characteristics, KFD is often mistaken for lymphoma, tuberculosis, systemic lupus erythematosus and even metastatic adenocarcinoma. Therefore, any physician who comes across a case of lymphadenopathy, should keep KFD in mind when consider differential diagnoses. KFD is self-limiting and resolution occurs is one to four months. There are no specific drugs for KFD and usual treatment is symptomatic, consisting of antipyretics and analgesics.

\section{Conclusions}

We describe a case of Kikuchi-Fujimoto Disease, a self-limiting necrotizing lymphadenitis that started with cervical lymph node swelling but progressed to left supraclavicular lymph node involvement, which makes it unique. Recognition of this disease is important as it can mimic lymphoma or even metastatic adenocarcinoma. Early diagnosis and treatment can help avoid unnecessary testing and improper treatments among patients. Correctly recognizing the symptoms of KFD can also save one from the emotional stress of misdiagnosis.

\section{Consent}

Written informed consent for publication of their clinical details and clinical images was obtained from the patient.

\section{Data availability}

All data underlying the results are available as part of the article and no additional source data are required.
1. Chiu CF, Chow KC, Lin TY, et al.: Virus infection in patients with histiocytic necrotizing lymphadenitis in Taiwan. Detection of Epstein-Barr virus, type I human T-cell lymphotropic virus, and parvovirus B19. Am J Clin Pathol. 2000; 113(6): 774-81.

PubMed Abstract | Publisher Full Text

2. Bosch X, Guilabert A, Miquel R, et al.: Enigmatic Kikuchi-Fujimoto disease: a comprehensive review. Am J Clin Pathol. 2004; 122(1): 141-152. PubMed Abstract | Publisher Full Text

3. Hudnall SD, Chen T, Amr S, et al:: Detection of human herpesvirus DNA in Kikuchi-Fujimoto disease and reactive lymphoid hyperplasia. Int J Clin Exp Pathol. 2008; 1(4): 362-368 PubMed Abstract | Free Full Text

4. Huh J, Kang GH, Gong G, et al:: Kaposi's sarcoma-associated herpesvirus in Kikuchi's disease. Hum Pathol. 1998; 29(10): 1091-1096. PubMed Abstract | Publisher Full Text

5. Yena A, Fearneyhough P, Raimer SS, et al.: EBV-associated Kikuchi's histiocytic necrotizing lymphadenitis with cutaneous manifestations. J Am Acad Dermatol. 1997; 36(2 Pt 2): 342-346.

PubMed Abstract | Publisher Full Text

6. Byun JH, Park SE, Nam SO, et al:: Three children of meningoencephalitis with Kikuchi necrotizing lymphadenitis. Brain Dev. 2018; 40(3): 251-255. PubMed Abstract | Publisher Full Text

7. Deaver $\mathrm{D}$, Horna $\mathrm{P}$, Cualing $\mathrm{H}$, et al.: Pathogenesis, diagnosis, and management of Kikuchi-Fujimoto disease. Cancer Control. 2014; 21(4): 313-21. PubMed Abstract | Publisher Full Text

8. Dumas G, Prendki V, Haroche J, et al:: Kikuchi-Fujimoto disease: retrospective study of 91 cases and review of the literature. Medicine (Baltimore). 2014; 93(24): 372-382.

PubMed Abstract | Publisher Full Text | Free Full Text

9. Shahid S, Alam SH, Hadley I: An Unusual Presentation of Kikuchi-Fujimoto Disease with Recurrent Subdural Effusion. Cureus. 2018; 10(3): e2302. PubMed Abstract | Publisher Full Text | Free Full Text 


\section{Open Peer Review}

\section{Current Peer Review Status:}

\section{Version 1}

Reviewer Report 12 May 2020

https://doi.org/10.5256/f1000research.21930.r62892

(C) 2020 Waqar S. This is an open access peer review report distributed under the terms of the Creative Commons Attribution License, which permits unrestricted use, distribution, and reproduction in any medium, provided the original work is properly cited.

\section{Syed Hamza Bin Waqar}

Internal Medicine, Civil Hospital Karachi, Dow University of Health Sciences, Karachi, Pakistan Needs to improve the verbal/grammatical check.. as malignancy, not malignance.

Run a grammar check thoroughly; check for repetition.

To rule out neoplastic disorder, you need to get an excisional biopsy - not perform blood tests (case presentation $\mathrm{p} 1$ ).

Add any serological tests like toxo, hiv, csd, cmv-ebv etc. that you might have done to rule out infectious causes of lymphadenopathy apart from IGRA which the authors have mentioned already.

Add any rheumatological tests like ANA etc. that might have been done to rule it out before proceeding to excisional biopsy.

Any rash that the pt might have/haven't noticed should be mentioned.

How does the involvement of supraclav lad make the case unique?

Final Comments:

Authors have done a great job in summarizing KFD and have beautifully presented the case. With only a little alteration in the case presentation by adding serological markers will make the case look more complete - although it's not necessary.

Is the background of the case's history and progression described in sufficient detail? Yes

Are enough details provided of any physical examination and diagnostic tests, treatment given and outcomes? 
Partly

Is sufficient discussion included of the importance of the findings and their relevance to future understanding of disease processes, diagnosis or treatment?

Yes

Is the case presented with sufficient detail to be useful for other practitioners?

Yes

Competing Interests: No competing interests were disclosed.

Reviewer Expertise: Internal Medicine.

I confirm that I have read this submission and believe that I have an appropriate level of expertise to confirm that it is of an acceptable scientific standard.

Reviewer Report 07 November 2019

https://doi.org/10.5256/f1000research.21930.r56268

(C) 2019 Yu K. This is an open access peer review report distributed under the terms of the Creative Commons Attribution License, which permits unrestricted use, distribution, and reproduction in any medium, provided the original work is properly cited.

Karl O. A. Yu

Division of Infectious Diseases, Department of Pediatrics, University at Buffalo, Buffalo, NY, USA

Sarfaz et al. report a rare (but probably it is not-so-rare) case of Kikuchi-Fujimoto lymphadenitis in a young adult. (disclosure: I just co-authored a recent case series on KFD). I am glad for this report to go out, as I suspect, based on my anecdotal experience, that this is not as rare as people think it is, but is probably under-diagnosed/under-reported. Seeing more reports as this in the literature may change conventional opinion.

I have a few suggestions to improve the manuscript:

The authors mention that testing for tuberculosis was done. I would suggest clarification as to why the IGRA was inconclusive. Was there a high background, or a failed mitogen testing. If the former -- this may be evidence for baseline inflammation (principally, IFNgamma/Th1 inflammation) in the patient's blood at that time -- this is potentially important. If the latter, this may be due to shipping issues, or evidence for transient anergy or other immunosuppression.

The authors say stains for acid fast bacilli were done and were negative. Was there a culture?

Was a PPD checked?

The authors state that histopathological confirmation of the diagnosis was made. Are 
microphotographs available for the reader themselves?

The authors state that the patient has "high lymphocytes." The patient's absolute lymphocyte count ( $2000 / \mathrm{uL}$ ) is NOT high.

"Epstein-Barr" is misspelled.

While not necessarily needed, since the authors did talk about the different infections associated with KFD, it would be enlightening to see what infectious workup was done for this patient, apart from an IGRA and an AFB stain.

With the suspicion of tuberculous meningitis, please clarify if anti-tuberculous therapy was started.

The authors also state that the case from from "South East Asia, Pakistan." I know that many Pakistanis and Indians are taught that their country is in southeast Asia -- but that is not the usual convention outside of Pakistan or India. Southeast Asia is conventionally the 10 states of ASEAN plus East Timor and Papua New Guinea. I would suggest the authors use "south Asia", or just say "Pakistan" to avoid any ambiguity.

Is the background of the case's history and progression described in sufficient detail? Yes

Are enough details provided of any physical examination and diagnostic tests, treatment given and outcomes?

Partly

Is sufficient discussion included of the importance of the findings and their relevance to future understanding of disease processes, diagnosis or treatment?

Yes

Is the case presented with sufficient detail to be useful for other practitioners?

Yes

Competing Interests: No competing interests were disclosed.

Reviewer Expertise: infectious disease; immunology; pediatrics; host/pathogen interactions

I confirm that I have read this submission and believe that I have an appropriate level of expertise to confirm that it is of an acceptable scientific standard, however I have significant reservations, as outlined above.

Author Response 31 Jul 2021

Shiza Sarfraz, Quaid-e-azam Medical College, Bhawalpur, Pakistan

IGRA being inconclusive secondary to delays in lab transport. 
IGRA was done there for PPD was deferred.

Lymphocytic percentage in is in fact increased per table one per the pathology lab.

Anti tuberculosis therapy was delayed till definitive diagnosis.

Competing Interests: No competing interests were disclosed.

The benefits of publishing with F1000Research:

- Your article is published within days, with no editorial bias

- You can publish traditional articles, null/negative results, case reports, data notes and more

- The peer review process is transparent and collaborative

- Your article is indexed in PubMed after passing peer review

- Dedicated customer support at every stage

For pre-submission enquiries, contact research@f1000.com 